\title{
Antioxidant and other biochemical defense responses of Macrotyloma uniflorum (Lam.) Verdc. (Horse gram) induced by high temperature and salt stress
}

\author{
Khalid Mohammed Naji ${ }^{1}$ and V. R. Devaraj ${ }^{j^{*}}$ \\ ${ }^{1}$ Department of Chemistry, Faculty of Science, Sana'a University, Sana'a, Yemen. \\ Phone: 009671219938; Fax: 009671214075. \\ ${ }^{2}$ Department of Biochemistry, Central College Campus, Bangalore University, Bangalore 560001 , India. \\ *Corresponding author: devaraj@bub.ernet.in \\ Received: 28 February 2011; Accepted: 02 September 2011
}

\begin{abstract}
High temperature and salinity are the major ecological factors challenging crop productivity in the arid and semiarid regions of the world. Effects of high temperature $\left(43-45^{\circ} \mathrm{C}\right)$ and salt stress $(0.6 \mathrm{M})$ on Macrotyloma uniflorum (Lam.) Verdc. (Horse gram), were evaluated in terms of antioxidants and antioxidant enzymes. Both treatments caused typical stress responses in this tropical leguminosae. Oxidative stress indicators such as $\mathrm{H}_{2} \mathrm{O}_{2}$, TBARS, and proline were significantly elevated. Similarly, the antioxidant enzymes superoxide dismutase (SOD; EC 1.15.1.1), guaiacol peroxidase (POX; EC 1.11.1.7) and acid phosphates (AP; EC 3.1.3.2) were significantly elevated while catalase (CAT; EC 1.11.1.6) was reduced. These treatments had contrasting effects on glutathione reductase (GR; EC1.6.4.2) and $\beta$-amylase (EC 3.2.1.1). While temperature stress caused increase in GR and decrease in $\beta$-amylase, salt stress caused a counter effect. Contrast was also observed in ascorbate and glutathione which increased in temperature stress and reduced in salt stress. SDS-PAGE analysis indicated entirely different protein profiles in temperature and salt stressed seedlings. Growth rate and fresh mass were affected to same extent, relative to their controls. Taken together these data describes the similarities and peculiarities of key biochemical responses of Horse gram to high temperatures and salinity.
\end{abstract}

Key words: Antioxidant enzymes, Horse gram; Isozymes, Oxidative stress, Salinity, Stress markers.

Abbreviations: TBARS: Thiobarbeturic acid reactive substances, PMSF: Phenyl methyl sulphonyl fluoride; ROS reactive oxygen species

\section{INTRODUCTION}

Plants are frequently exposed to major stress conditions such as low temperature, salt, drought, flooding, heat, oxidative stress and heavy metal toxicity, which adversely affect plant growth and productivity (Mahajan and Tuteja, 2005). One of the major effects is the generation and reactions of ROS (Liu and Huang, 2000; Shao et al., 2008). In order to limit oxidative damage under stress condition plants have developed a series of detoxification systems that break down the highly toxic ROS. The detoxification system is composed of enzymatic and non-enzymatic mechanisms. The enzymatic components 
include super oxide dismutase (SOD; EC 1.15.1.1), catalase (CAT; EC 1.11.1.6), peroxidase (POX; EC 1.11.1.7), ascorbate peroxidase (APX), dehydroascorbate reductase (DHAR), monodehydroascorbate reductase (MDAR) and glutathione reductase (GR; EC1.6.4.2). In addition to antioxidant enzymes, hydrolytic enzymes such as amylase and phosphatases have also been implicated in stress response (Shao et al., 2008; Scheidig et al, 2002; Olmos and Hellin, 1997).

The non-enzymatic mechanisms consist of antioxidants such as ascorbate, glutathione, tocopherol and carotenoids; proteins such as chaperones, dehydrins and HSPs and osmolytes such as proline, glycine betaine and raphinose (Sairam and Tyagi, 2004; Ashraf and Foolad, 2007).

Horse gram is considered a poor man's pulse as it offers a relatively cheap source of proteins for human consumption and livestock production. This work describes the main antioxidant responses and other stress specific biochemical defenses, differentially activated under high temperatures and salt stress in this underexplored tropical leguminosae species.

\section{MATERIALS AND METHODS}

Plant material and stress treatment: Seeds of Horse gram, Macrotyloma uniflorum (PHG-9 cultivar) were surface sterilized with $0.1 \% \mathrm{HgCl}_{2}$ for $20 \mathrm{sec}$ and washed immediately with distilled water many times. And sown in trays containing vermiculite, and irrigated daily with distilled water. Five days old plants, grown in vermiculite, in a controlled chamber at 26 ${ }^{\circ} \mathrm{C}$, and a photoperiod of $16 \mathrm{~h}$ light: $8 \mathrm{~h}$ dark.

High-temperature stress was applied by treatment of seedlings at $38-39^{\circ} \mathrm{C}$ for $2 \mathrm{~h}$ followed by exposure to $43-45$ ${ }^{\circ} \mathrm{C}$ for $2.5 \mathrm{~h}$.

Salt stress: Five days old seedlings were transferred into dishes containing 1/2 strength sterile Hoagland's nutrient solution with added micronutrients (Allen, 1968). The seedlings were grown at $26^{\circ} \mathrm{C}$ under $16 \mathrm{~h}$ light: $8 \mathrm{~h}$ dark photoperiod. Salt stress was induced by incubating plants in half-strength Hoagland's nutrient solution containing $\mathrm{NaCl}$ at a final concentration of $600 \mathrm{mM}$ for $48 \mathrm{~h}$. Plants grown on halfstrength Hoagland's medium without $\mathrm{NaCl}$ served as control.

Enzyme extraction and antioxidants: Frozen shoots were homogenized with $50 \mathrm{mM}$ sodium phosphate buffer $(\mathrm{pH}$
7.5) containing $1 \mathrm{mM}$ PMSF and $5 \mathrm{mM} \beta$-mercaptoethanol. The homogenate was centrifuged at $5,600 \times \mathrm{g}$ for $20 \mathrm{~min}$. The supernatant was used as source of enzymes, antioxidants, and other components. All the steps in the preparation of the enzyme extract were carried out between 0 to $4{ }^{\circ} \mathrm{C}$. Soluble protein content was determined according to the method of Lowry et al. (1951) with BSA as the standard.

Determination of $\mathrm{H}_{2} \mathrm{O}_{2}$, ascorbic acid and proline: Hydrogen peroxide content was determined according to the method of Velikova et al. (2000), ascorbic acid and dehydroascorbic acid contents were estimated according to Okamura (1980) with the modification adopted by Knorzer et al. (1996). Free proline was extracted from $0.5 \mathrm{~g}$ of fresh tissue in $3 \%$ aqueous sulphosalicylic acid and estimated by ninhydrine method according to Bates et al. (1973).

Determination of membrane damage: Lipid peroxidation (MDA) in the seedling samples was measured as indicator of membrane damage. The MDA reacts with thiobarbituric acid (TBA) to form MDA-TBA complex named TBARS which was measured by reading absorbance at $532 \mathrm{~nm}$. Correction was applied by subtracting the absorbance at $600 \mathrm{~nm}$ using extinction coefficient of $156 \mathrm{mM}^{-1} \mathrm{~cm}^{-1}$ (Madhava Rao and Stresty, 2000).

Measurements of GSH: The amount of $0.5 \mathrm{~g}$, of frozen plant tissue was ground to fine powder, and homogenized in $1.0 \mathrm{ml}$ of $3 \%$ trichloroacetic acid and centrifuged at 12,000 rpm for 15 min at $4{ }^{\circ} \mathrm{C}$. Reduced glutathione was determined according to Eyer and Podhradský (1986).

Assay of enzymes: Acid phosphatase (AP; EC 3.1.3.2) - activity was assayed according to the method of Hoerling and Svensmark (1976) employing $\alpha$-naphthyl phosphate or $p$-nitrophenyl phosphate as substrates. Each unit of activity is defined as the number of $\mu$ moles of $\alpha$-naphthol or $p$-nitrophenol released per minute. In-gel assay was carried out after electrophoretic separation of phosphatase isozymes on native (9\%) polyacrylamide gels at $4^{\circ} \mathrm{C}$. The enzyme bands were detected using $\alpha$-naphthyl phosphate as substrate and fast blue RR as coupling dye.

$\beta$-Amylase (EC 3.2.1.1) - activity was assayed according to the method of Shuster and Gifford (1962). The activity unit was expressed in terms of $\mu$ moles of maltose formed per minute. $\beta$-amylase isozymes were separated on non denaturizing polyacrylamide gels ( $9 \%$ ) at $100 \mathrm{~V}$ for $2 \mathrm{~h}$ at 
$4^{\circ} \mathrm{C}$. Gels were then soaked in substrate $(2 \%$ soluble starch) for $30 \mathrm{~min}$ at $27^{\circ} \mathrm{C}$ and incubated in $0.025 \%$ acidified iodine solution for $5 \mathrm{~min}$.

Catalase (CAT; EC 1.11.1.6) - activity was measured by following the decline in $\mathrm{A}_{240}$ of $\mathrm{H}_{2} \mathrm{O}_{2}\left(\varepsilon=36 \mathrm{M}^{-1} \mathrm{~cm}^{-1}\right)$ according to the method of Aebi (1984) in a reaction mixture containing $20 \mu$ l enzyme extract in $50 \mathrm{mM}$ sodium phosphate buffer (pH 7.0). The reaction was started by adding $15 \mathrm{mM}$ of $\mathrm{H}_{2} \mathrm{O}_{2}$ as a final concentration and its consumption was measured for about $30 \mathrm{~S}$ at $240 \mathrm{~nm}$. In-gel assay for CAT isozymes were performed on non-denaturizing gels (9\%) electrophoresed at $100 \mathrm{~V}$ for $2 \mathrm{~h}$ at $4{ }^{\circ} \mathrm{C}$. Gels were soaked in $3.27 \mathrm{mM} \mathrm{H}_{2} \mathrm{O}_{2}$ for $15 \mathrm{~min}$, rinsed with water, and stained with $2 \%$ potassium ferricyanide followed by $2 \%$ ferric chloride to visualize the bands (Prasad et al., 1995).

Glutathione reductase (GR; EC1.6.4.2) - was assayed by monitoring the GSSG dependent NADPH oxidation according to the method of Edwards et al. (1994). GR isozymes were separated on non denaturized gels (9\%) at $100 \mathrm{~V}$ for $2 \mathrm{~h}$ at $4{ }^{\circ} \mathrm{C}$., soaked in $50 \mathrm{mM}$ Tris-HCl buffer ( $\mathrm{pH}$ 7.5) containing $10 \mathrm{mg}$ MTT, $10 \mathrm{mg}$ 2, 6- dichlorophenol indophenol, $3.4 \mathrm{nM}$ GSSG, and $0.4 \mathrm{mM} N A D P H$.

Guaiacol peroxidase activity (POX; EC 1.11.1.1) - was measured by monitoring the formation of tetra guaiacol at 470 $\mathrm{nm}\left(\mathrm{e}=26.6 \mathrm{mM}^{-1} \mathrm{~cm}^{-1}\right)$ using $\mathrm{H}_{2} \mathrm{O}_{2}$ as substrate according to Chance and Machly (1955). One unit of peroxidase is defined as the amount of enzyme that caused the formation of $1 \mathrm{mM}$ of tetra-guaiacol per minute. POX isozymes separated on $9 \%$ native acrylamide gels were incubated in a mixture of O-dianisidine- $\mathrm{HCl}$ in acetate buffer (pH 5.5) for $30 \mathrm{~min}$ at room temperature. Gels were then transferred to $100 \mathrm{mM}$ $\mathrm{H}_{2} \mathrm{O}_{2}$ until visible bands developed.

Superoxide dismutase (SOD; EC 1.15.1.1) - activity was determined using the photochemical method of Beauchamp, Fridovich (1971), and Mirsa and Fridovich (1977), by measuring its ability to inhibit the photochemical reduction of nitroblue tetrazolium (NBT). A $3.0 \mathrm{ml}$ reaction mixture contained $50 \mathrm{mM}$ pot.phosphate buffer (pH 7.8), 13 $\mathrm{mM}$ methionine, $75 \mathrm{mM}$ NBT, 2 mM riboflavin, $0.1 \mathrm{mM}$ EDTA, and 10-150 $\mu$ l enzyme extract. Riboflavin was added at the end. The tubes were shaken and placed $15 \mathrm{~cm}$ below 40-W lamps. The reaction was initiated by exposure to light and arrested after 15 min by removal of light. The absorbance of the reaction mixture at $560 \mathrm{~nm}$ was read against a reaction mixture lacking enzyme, which developed maximum color (control value). One unit of the enzyme is defined as the amount of enzyme which can inhibit the reaction (color development) by $50 \%$.

Electrophoretic analysis: Non-denaturing discontinues slab gel electrophoresis was carried out essentially according to the method of Davis (1964), SDS-PAGE was performed according to Laemmli (1970) using 10\% acrylamide resolving gel and $5 \%$ stacking gel.

Statistical analysis: All data are expressed as means of triplicate experiments unless mentioned otherwise. Comparisons of means were performed using graph Pad prism software. Data were subjected to a one-way analysis of variance (ANOVA), and the mean differences were compared $(P<0.05)$.

\section{RESULTS AND DISCUSSION}

High temperature, drought, and salt stress, are major ecological factors, which affect agriculture and prevent crop plants from expressing their full genetic potential. These abiotic stresses differentially affect cellular homeostasis in plant by the formation of reactive oxygen species (ROS). The ROSs in turn, cause oxidative damage to membrane, lipids, proteins, and nucleic acids (Desikan et al., 2003; Moller et al., 2007; Hussain et al., 2008). A well coordinated rapidly responding antioxidant system consisting of several antioxidant enzymes and redox metabolites limit these damages. However, when the extent of ROS production exceeds the antioxidant capability, cellular damages ensue. Horse gram, extensively cultivated in dry climatic conditions and less fertile lands is subjected to a great deal of abiotic stresses, thereby limiting its yield. Therefore, an understanding of the biochemical basis of the response during applied abiotic stresses such as high temperature and salt would help to improve its agronomic potential.

Horse gram seedlings experienced a general inhibition of shoots and root growth under high temperature and salt stress (data not shown). Overall reduction in the growth of Horse gram during both the stresses indicated that the effects were similar to those observed during prolonged drought and high salinity (Boyer, 1982; Neumann, 2008). 
Table 1. Antioxidants and other stress markers in horse gram seedling*

\begin{tabular}{ccccc}
\hline & \multicolumn{3}{c}{ Stress } \\
\cline { 2 - 5 } & \multicolumn{2}{c}{ Temperature } & \multicolumn{3}{c}{ Salinity } \\
\cline { 2 - 5 } & \multicolumn{1}{c}{ C } & S & C & S \\
\hline Hydrogen peroxide $(\mathrm{mM} / \mathrm{g})$ & $11.61 \pm 0.39$ & $12.93 \pm 0.75$ & $6.463 \pm 0.29$ & $4.082 \pm 0.13$ \\
MDA (TBARS) $(\mathrm{mM} / \mathrm{g})$ & $4.313 \pm 0.21$ & $7.478 \pm 0.23$ & $3.523 \pm 0.16$ & $4.647 \pm 0.08$ \\
Ascorbic Acid $(\mathrm{mg} / \mathrm{g})$ & $3.54 \pm 0.25$ & $8.85 \pm 0.24$ & $4.97 \pm 0.25$ & $3.78 \pm 0.67$ \\
Proline $(\mu \mathrm{g} / \mathrm{g})$ & $3.14 \pm 0.094$ & $8.304 \pm 0.09$ & $0.246 \pm 0.04$ & $0.388 \pm 0.017$ \\
Glutathione $(\mathrm{GSH})(\mathrm{mM} / \mathrm{g})$ & $154.7 \pm 3.65$ & $205.7 \pm 3.63$ & $142.1 \pm 5.18$ & $135.7 \pm 3.86$ \\
\hline
\end{tabular}

*each values is mean $\pm S E(n=4) ; C$, control; $S$, stressed seedlings

Hydrophilic antioxidants such as glutathione and ascorbic acid are indispensable components of the antioxidant system which scavenge ROS (Foyer and Noctor, 2005). Glutathione and ascorbic acid levels were elevated under high temperature (Table 1) while ascorbic acid increased by $250 \%$; the GSH increased only by $30 \%$ over the control. On the other hand, both the antioxidants were reduced, albeit moderately during salt stress (Table 1).

Such increase in levels of hydrophilic antioxidants, GSH, ascorbic acid and proline under temperature stress, and their reduction under salt stress (except a slight increase in proline) suggested that horse gram expresses a more efficient antioxidant response to high temperatures than for salt stress (Table 1). Ascorbic acid in association with other components of the antioxidant system protects plants against oxidative damage resulting from aerobic metabolism, photosynthesis and a range of pollutants (Waheed et al., 2007). Enhanced production of ascorbic acid and GSH has been correlated to reduced ROS production under temperature stress (Xu et al., 2006). Similarly, increased levels of these two hydrophilic antioxidants in horse gram support the fact that GSH and ascorbate protect the plant against oxidative damage.

Compatible solutes, such as proline, glycine-betaine, and sugars act as ROS scavengers and proteins stabilizers, and are essential components of temperature and salt tolerance mechanisms (Kumar et al., 2007). Drought and salt stress induced accumulation of proline is well documented and tolerant species have been shown to express higher levels of proline and its precursors than the susceptible ones (Ashraf and Foolad, 2007). Horse gram seedlings stressed with high temperature showed a $\sim 250 \%$ increase in proline content, while salt stressed seedlings exhibited only a $50 \%$ increase. Available literature suggests that proline levels are regulated at the $\Delta^{1}$-pyrolline carboxylate metabolism (Hong et al., 2000). From the levels of proline estimated during high temperature stress, a possible role could be suggested for $\triangle^{1} P C A$ carboxylase in regulation of proline metabolism in horse gram.

Malondialdehyde (MDA), a product of lipid peroxidation is considered as an indicator of oxidative damage (André et al., 2006). A correlation appears to exist between lipid peroxidation and membrane permeability. A two-fold increase in the degree of peroxidation (Table 1) in temperature stressed seedlings compared to controls, suggested greater oxidative damage. Although the MDA levels were elevated under salt stress (30\%), as compared to temperature stress the extent of lipid peroxidation was less pronounced.

Stress-induced generation of free radicals could alter chromatin organization that facilitates the differential expression of a number of genes. Extensive heat shock and resultant production of ROS are known to cause DNA damage (Apel and Hirt 2004). Commonly noticed modifications in DNA are hydroxyl guanine, conjugation of MDA with guanine, and changes in methylation resulting in altered expression of genes (Moller et al., 2007). Unaltered mobility of nuclear DNA of stressed horse gram seedlings relative to control indicated no significant alteration in the chromatin and subsequent damages to DNA (data not shown).

As a part of the enzymatic component of antioxidant system of plant response, antioxidant enzymes contribute significantly to ROS detoxification. The coordinate function of antioxidant enzymes such as SOD, POX, CAT and GR helps in 
processing of ROS and regeneration of redox ascorbate and glutathione metabolites (Almeselmani et al., 2006). Resistance to high temperature and salt stress are correlated with increased acclimatization to the concerned stress (Agarwal and Pandey, 2004). Horse gram seedlings subjected to stress responded differentially to temperature and salt stress in terms of antioxidant enzymes. During temperature stress POX, GR, and SOD were elevated and CAT was diminished. On the contrary, during salt stress, only POX and SOD were elevated while CAT and GR were reduced (Figure 1).

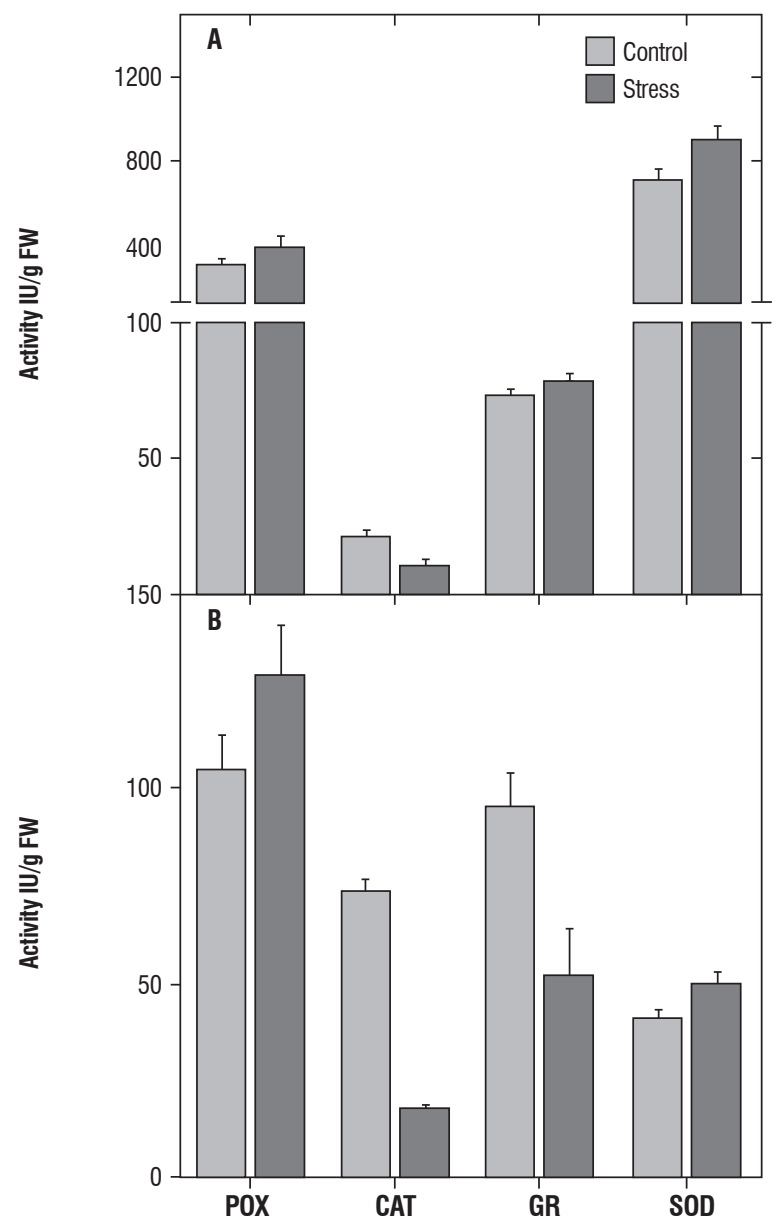

Figure 1. Levels of antioxidant enzymes of Horse gram seedlings exposed to heat at $45^{\circ} \mathrm{C}$ for $2.5 \mathrm{~h}(\mathrm{~A})$ and $600 \mathrm{mM} \mathrm{NaCl}$ (B). Data represent mean values $\pm \mathrm{SE}$ of duplicate of three separate experiments.

Superoxide dismutase (SOD) converts the first product of the univalent reduction of $\mathrm{O}_{2}$ to $\mathrm{H}_{2} \mathrm{O}_{2}$ which must then be processed by CAT and/or peroxidases. Therefore, the significant increase in the levels of SOD during both the stresses suggests production of considerable amounts of superoxide and a proportional response by the stressed horse gram seedlings. The levels of SOD activity also appear to correlate with the levels of $\mathrm{H}_{2} \mathrm{O}_{2}$ during both stresses. Increased levels of SOD are reported from drought stressed Arabidopsis, sunflower, maize, wheat, and tomato (Unyayar and Cekic, 2005). Levels of SOD are also correlated with $\mathrm{NaCl}$ tolerance, probably due to effective scavenging of $\mathrm{O}_{2}$. Results with high temperature and $600 \mathrm{mM} \mathrm{NaCl}$ stress in horse gram are in agreement with those reported for Cassia angustifolia (Agarwal and Pandey, 2004) and salt tolerant cultivars of Allium species (Csiszar et al., 2007). However, our results are in contrast with salt stressed Catharanthus roseus (Jaleel et al., 2007), potato (Rahnama and Ebrahimzadeh, 2005) and wheat seedlings which showed a initial increase at $50 \mathrm{mM} \mathrm{NaCl}$ and subsequent decline with increasing concentration of salt (Esfandiari et al., 2007). Increased enzyme activity in salt-stressed horse gram did not accompany any alterations in isozyme pattern. This indicated the over expression of the major isozyme which appeared to be Cu-Zn type as judged by the electrophoretic mobility (Figure 2D). In addition, it is also believed that the same isozyme participates in detoxification of $\mathrm{O}_{2}$. under normal and stressed conditions. Intracellular levels of $\mathrm{H}_{2} \mathrm{O}_{2}$ are mainly regulated by CAT and POX (Blokhina et al., 2003). A number of plants have been shown to express increased activity of CAT and POX in order to cope with toxic levels of $\mathrm{H}_{2} \mathrm{O}_{2}$ (Agarwal and Pandey, 2004; Rahnama and Ebrahimzadeh, 2005; Nagesh Babu and Devaraj, 2008). Contrary to the aforementioned reports, horse gram showed increased POX and reduced levels of CAT under both the stresses. However, CAT levels in horse gram closely resembled drought stressed wheat seedlings (Bakalova et al., 2004). As CAT is the major enzyme involved in the metabolism of $\mathrm{H}_{2} \mathrm{O}_{2}$ produced by the SOD, its inhibition under both types of stress could contribute to elevated levels of $\mathrm{H}_{2} \mathrm{O}_{2}$ (Table 1). As the CAT levels in horse gram are not induced under these conditions, the plant seems to have an inefficient mechanism for $\mathrm{H}_{2} \mathrm{O}_{2}$ elimination. Further, relatively higher levels of $\mathrm{H}_{2} \mathrm{O}_{2}$ observed under temperature stress than salt stress appear to correlate with higher levels of SOD and diminished levels of CAT. 


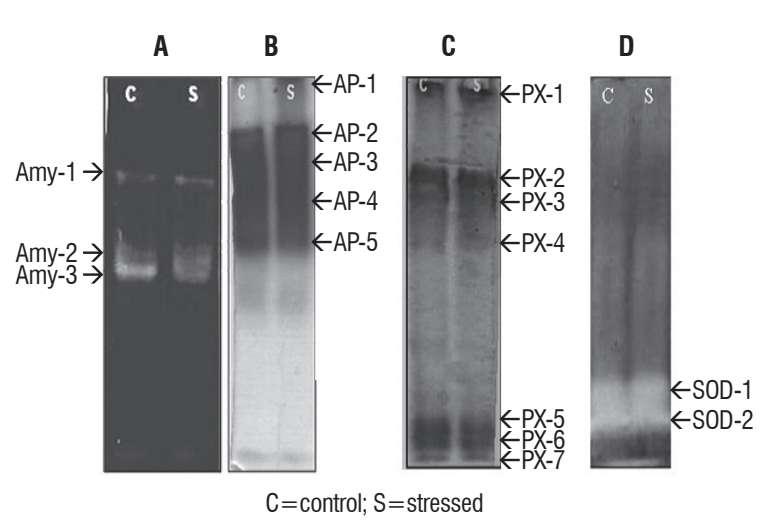

Figure 2. Zymogram of $\beta$-amylase (A), acid phosphatase (B), peroxidase (C), superoxide dismutase (SOD) (D) activities from horse gram seedlings exposed to $600 \mathrm{mM} \mathrm{NaCl}$.

The isozyme pattern of CAT under high temperature stress did not show any alteration in pattern or intensity (Figure 3D) indicating absence of any significant role of CAT in horse gram. Unlike CAT, POX levels increased under both stresses (Figure 1). In the absence of considerable CAT the onus of detoxifying $\mathrm{H}_{2} \mathrm{O}_{2}$ may lie on $\mathrm{POX}$ in horse gram under temperature and salt stress. POX activity is known to increase along with CAT, SOD and $\mathrm{GR}$ in response to various environmental stresses such as salt, drought and $\mathrm{H}_{2} \mathrm{O}_{2}$ (Shigeoka et al., 2002; Tsai et al., 2005; Hong et al., 2007). Apart from variations in POX levels among different plants, variations have also been noticed among cultivars of plants (Khan and Panda, 2008). There are also contrasting reports as far as the relationship between POX activity and salt tolerance, indicating both negative (Demiral and Turkan, 2005) and positive (Khan and Panda, 2008) correlation. Observed levels of $\mathrm{H}_{2} \mathrm{O}_{2}$ and POX levels (Figure 1) show a possible induction of $\mathrm{POX}$ by $\mathrm{H}_{2} \mathrm{O}_{2}$ in both salt and temperature stressed horse gram. This is also substantiated by the prevailing levels of MDA, the lipid peroxidation product. Examinations of isozyme patterns of POX indicated the participation of different set of isozymes under salt and temperature stress in horse gram. Where as temperature stressed seedlings indicated the expression of a new isozyme in addition to induction of major cationic from (Figure 2), the salt stressed seedlings showed induction of cationic bands observed in controls (Figure 3) without any new isoforms. Glutathione reductase (GR) plays a key role in oxidative stress by converting the oxidized glutathione (GSSG) to reduced glutathione (GSH) and maintaining a high GSH/GSSG ratio (Irishimovitch and Shapira, 2000). The enzyme levels were enhanced under heat stress and reduced under salt stress in horse gram. Increased GR activity in leaves of sugar beet plant has been closely related with salt tolerance capacity (Bor et al., 2003). Elevated levels of GR under temperature stress in horse gram coincide with drought stressed Arabidopsis (Jung, 2004) and water stressed Allium species (Csiszar et al., 2007).Considering the common effect of dehydration by high temperature and salt stress, higher levels of GR could be related to high temperature tolerance in horse gram. Reduction of GR in horse gram stressed with salt is similar to salt stressed wheat seedlings (Esfandiari et al., 2007). Reduced levels of GR, GSH and less significant levels of POX under salt stress indicated reduced turnover of GSH and less active Halliwell-Asada cycle. On the other hand, greater levels of GSH and GR under temperature suggested tolerance via Halliwell-Asada cycle as observed for a number of plants (Koca et al., 2007). Two hydrolytic enzymes involved in metabolite regulation were also estimated during salt and temperature stress. The amylase showed a decline under temperature stress (Figure 4A) and enhancement under salt stress (Figure 4B). Increased amylase activity has been linked to increased maltose content (Kaplan and Guy, 2004; Nielsen et al., 1997), and its levels are modulated in response to osmotic, drought, salt and heat stress (Datta et al., 1999; Dreier et al., 1995; Yang et al., 2001; Sung 2001). There are also scanty reports of induction of either transcripts and/or activity of amylase (Kreps et al., 2002; Seki et al., 2001; Jung et al., 2003). The elevated levels of amylase (Figure 2-A) in saltstressed horse gram seedlings could be due to induction of amylase by $\mathrm{NaCl}$ induced osmotic signals. Difference in amylase levels between salt and temperature stress is also evident by zymogram patterns (Figure 2-A and 3-A).

Acid phosphatase expression is induced due to factors like water deficit, salt and metal stresses. The induction could be secondary to inorganic phosphate generating enzymes, like PFK and PEP carboxylase (Duff et al., 1994). Horse gram stressed with both temperature and salt showed increased acid phosphatase activities. However, the increase was more pronounced in salt stress than in temperature stress (Figure 4). 


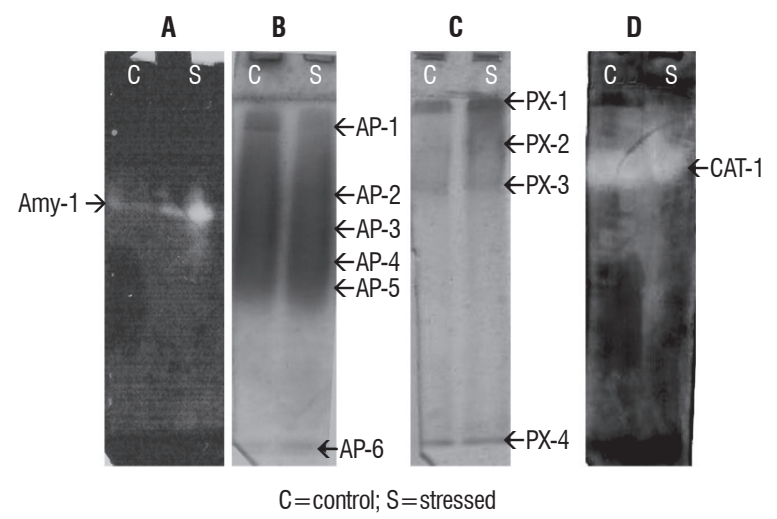

Figure 3. Zymogram of $\beta$-amylase $(A)$, acid phosphatase $(B)$, peroxidase (C), Catalase (D) from horse gram seedlings exposed to temperature stress $\left(40-45^{\circ} \mathrm{C}\right)$.

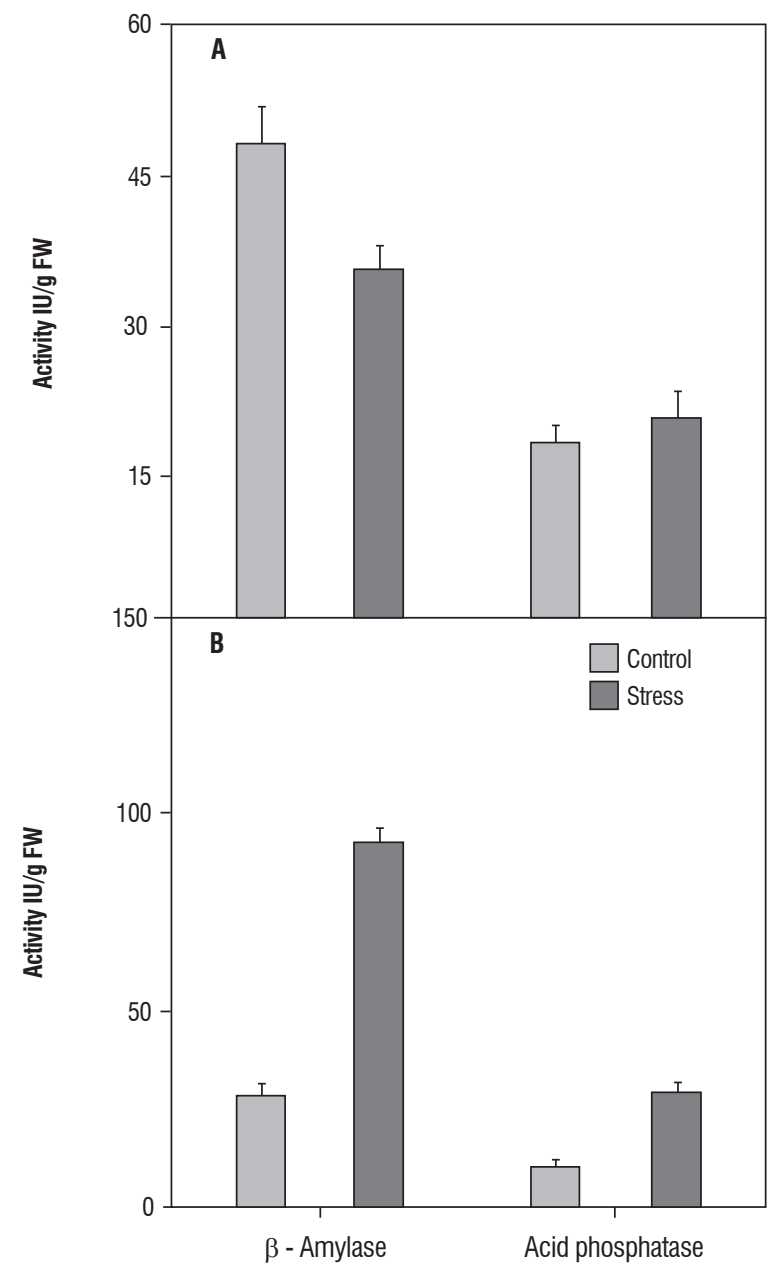

Figure 4. Levels of $\beta$-amylase and acid phosphatase in Horse gram seedling exposed to heat at $45^{\circ} \mathrm{C}$ for $2.5 \mathrm{~h} \mathrm{(A)}$ and $600 \mathrm{mM} \mathrm{NaCl}$ stress (B).Data represent mean values \pm SE of duplicate of three separate replicates.
Olmos and Hellin (1997) observed that acid phosphatase are known to act under salt and water stress by maintaining a certain level of inorganic phosphate which can be cotransported with $\mathrm{H}^{+}$along a gradient of proton motive force. In few cases, phosphatase activities are independent of phosphate levels (Szabo-Negy et al., 1992). The elevated level of AP in horse gram is suggestive of a common sensor mechanism for heat, drought, and salt stress endurance. Probably, temperature and salt-induced loss of water (change in osmolarity) might have elicited the signal for elevated expression of acid phosphatase.

The observed differences between high temperature and salt stress responses in horse gram were also reflected in the electrophoretic (SDS-PAGE) protein patterns (Figure 5). This is in line with the notion that distinct signaling pathways and biochemical responses are induced by salt and temperature stresses. Taken together these data describes key biochemical stress responses of horse gram upon high temperatures and salt stress providing the basic information needed for future biotechnological programs toward improvement of crop productivity, mainly in tropical regions where the hottest climates and soil salinity are prevalent.

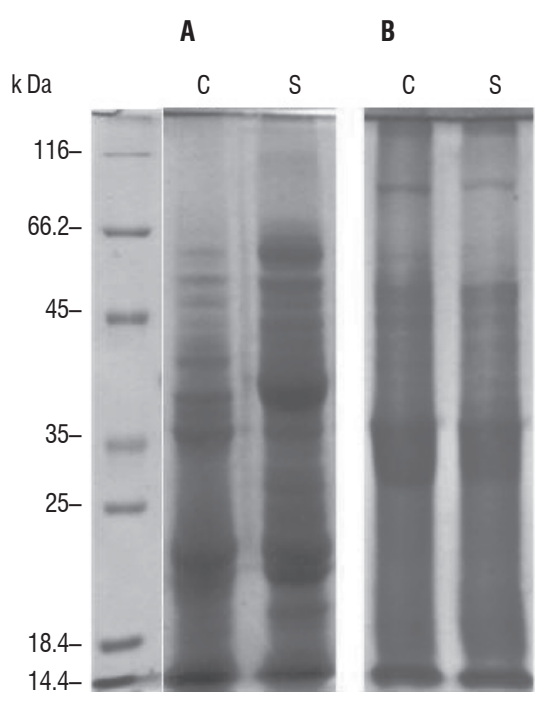

Figure 5. Protein patterns (10\% SDS-PAGE) of Horse gram seedlings exposed to (A) High temperature stress, (B) $600 \mathrm{mM} \mathrm{NaCl}$. 


\section{REFERENCES}

Aebi H (1984) Catalase in vitro. Methods of Enzymology 105: 121-126.

Agarwal S, Pandey V (2004) Antioxidant enzyme responses to $\mathrm{NaCl}$ stress in Cassia angustifolia. Biol Plant 48: 555-560.

Almeselmani M, Deshmukh PS, Sairam RK, Kushwaha SR, Singh TP (2006) Protective role of antioxidant enzymes under high temperature stress. Plant Sci. 171: 382-388.

André DAN, José TP, Joaquim EF, Carlos Eduardo BD, Enéas GF (2006) Effect of salt stress on antioxidative enzymes and lipid peroxidation in leaves and roots of salt-tolerant and salt-sensitive maize genotypes. Environ. Exp. Bot. 56: 87-94.

Apel K, Hirt H (2004) Reactive oxygen species: metabolism, oxidative stress, and signal transduction. Annu. Rev. Plant Biol. 55: 373-399.

Ashraf M, Foolad MR (2007) Roles of glycine betaine and proline in improving plant abiotic stress resistance. Environ. Exp. Bot. 59: 206-216.

Bakalova R, Ohba H, Zhelev Z, Ishikawa M, Baba Y (2004) Quantum dots as photosensitizers. Nat Biotechnol. 22: 1360-1.

Blokhina 0, Virolainen E, Kkurt V, Fagersted T (2003) Antioxidants, Oxidative Damage and Oxygen Deprivation Stress: a Review. Ann Bot. 91: 179-194.

Bor M, Ozdemir F, Turkan I (2003) The effect of salt stress on lipid peroxidation and antioxidants in leaves of sugar beet Beta vulgaris $\mathrm{L}$. and wild beet Beta maritima L. Plant Sci. 164: 77-84.

Boyer JS (1982) Plant productivity and environment. Science 218: 443-448.

Chance M, Machly AC (1955) Assay of catalases and peroxidases, Meth Enzymol 2: 764-817.

Csiszar J, Lantos E, Tari I, Madoşa E, Wodala B, Vashegyi A, Horvath F, Pecsvaradi A, Szabo M, Bartha B, Galle A, Lazar A, Coradini G, Staicu M, Postelnicu S, Mihacea S, Nedelea G, Erdei L (2007) Antioxidant enzyme activities in Allium species and their cultivars under water stress. Plant Soil Environ. 53: 517-523.

Datta R, Selvi MT, Seetharama N, Sharma R (1999) Stress-mediated enhancement of beta-amylase activity in pearl millet and maize leaves is dependent on light. J. Plant Physiol.154: 657-664.

Desikan R, Neill SJ, Hancock JT (2003) Nitric oxide signaling in plants. New Phytologist 159:11-35.

Dreier W, Schnarrenberger C, Borner T (1995) Light and stress-dependent enhancement of amylolytic activities in white and green barley leaves: betaamylases are stress-induced proteins. J. Plant Physiol. 145: 342-348.

Duff SMG, Sarath G, Plaxton WC (1994) The role of acid phosphatases in plant phosphorus metabolism. Physiol. Planta 90: 791-800.

Esfandiari FY, Min Villanueva JA, Wong, Donna HF, Samuel WH, Charles H (2007) S-Adenosylmethionine Attenuates Hepatic Lipid Synthesis in Micropigs Fed Ethanol With a Folate-Deficient Diet Alcoholism. Clinical and Exp. Research 31: 1231-1239.

Eyer P, Podhradský D (1986) Evaluation of the micromethod for determination of glutathione using enzymatic cycling and Ellman's reagent. Anal. Biochem. 153: $57-66$.

Foyer CH, Noctor G (2005) Oxidant and antioxidant signaling in plants: a reevaluation of the concept of oxidative stress in a physiological context. Plant Cell and Environ. 28: 1056-1071.

Hoerling N, Svensmark 0 (1976) Carboxyl esterase with different substrate specificity in human brain extracts. J. Neurochem. 27: 523-528.

Hong JP, Byun MY, Koo DH, An K, Bang JW, Chung IK, An G, Kim WT (2007) Suppression of RICE TELOMERE BINDING PROTEIN1 results in severe and gradual developmental defects accompanied by genome instability in rice. Plant Cell 19: 1770-1781.

Hong Z, Lakkineni K, Zhang Z, Verma DPS (2000) Removal of feedback inhibition of $\Delta^{1}$-pyrroline-5-carboxylate synthetase results in increased proline accumulation and protection of plants from osmotic stress. Plant Physiol. 122: 1129-1136.

Hussain TM, Chandrasekhar T, Hazara M, Sultan Z, Saleh BK, Gopal GR (2008) Recent advances in salt stress biology- a review. Biotech Mol Biol Rev. 3: 8-13.

Irihimovitch V, Shapira M, (2000) Glutathione Redox Potential Modulated by Reactive Oxygen Species Regulates Translation of Rubisco Large Subunit in the Chloroplast. J. Biol. Chem. 275: 16289-16295.

Jaleel CA, Gopi R, Manivannan P, Panneerselvam R (2007) Responses of antioxidant defense system of Catharanthus roseus (L.) G. Don., to paclobutrazol treatment under salinity. Acta Physiol Plant 29: 205-209.

Jung SH, Lee JY, Lee DH (2003) Use of SAGE technology to reveal changes in gene expression in Arabidopsis leaves undergoing cold stress. Plant Mol. Biol. 52: 553-67.

Jung S (2004) Variation in antioxidant metabolism of young and mature leaves of Arabidopsis thaliana subjected to drought. Plant Sci. 166: 459-466.

Kaplan F, Kopka J, Haskell DW, Zhao W, Schiller KC, Gatzke N, Sung DY, Guy CL (2004) Exploring the Temperature-Stress Metabolome of Arabidopsis. Plant Physiol. 136: 4159-4168.

Khan MH, Panda SK (2008) Alterations in root lipid peroxidation and antioxidative responses in two rice cultivars under $\mathrm{NaCl}$-salinity stress. Acta Physiol Plant 30: 81-89.

Koca H, Bor M, Özdemir F, Türkan I (2007) The effect of salt stress on lipid peroxidation, antioxidative enzymes and proline content of sesame cultivars. Environ. Exp. Bot. 60: 344-351.

Kreps JA, Wu Y, Chang H-S, Zhu T, Wang X, Harper JF (2002) Transcriptome changes for Arabidopsis in response to salt, osmotic, and cold stress. Plant Physiol. 230: 2129-2141.

Kumar K, Devi SS, Krishnamurthi K, Kanade GS, Chakrabarti T (2007) Enrichment and isolation of endosulfan degrading and detoxifying bacteria. Chemosphere 68: 317-322.

Laemmli, (1970) Cleavage of structural proteins during the assembly of the head of bacteriophage T4. Nature 227: 680-685.

Liu X, Huang B (2000) Heat Stress Injury in Relation to Membrane Lipid Peroxidation in Creeping Bentgrass. Crop Sci. 40: 503-510.

Lowry OH, Rosebrough NJ, Farr Al, Randall RI, (1951) Protein measurement for the folin phenol reagent. J. Biol. Chem. 193: 265-275.

Madhava Rao KV, Sresty TVS, (2000) Antioxidative parameters in the seedlings of pigeonpea (Cajanus Cajan L. Millspaugh) in response to $\mathrm{Zn}$ and Ni stresses. Plant Sci. 157: 113-28.

Mahajan S, Tuteja N (2005) Cold, salinity and drought stresses: An overview. Arch. Biochem, Biophys. 444: 139-158.

Misra HP, Fridovich I (1977) Superoxide dismutase: "positive" spectrophotometric assays. Anal. Biochem. 70: 553-560.

Møller IM, Jenesen PE, Hanssen A (2007) oxidative modification to cellular components in plants. Annu. Rev. Plant Biol. 58: 459-481.

Nagesh Babu R, Devaraj VR (2008) High temperature and salt stress response in French bean (Phaseolus vulgaris). Aust. J. Crop Sci. 2:40-48.

Neumann PM (2008) Coping Mechanisms for Crop Plants in Drought-prone Environments. Ann. Bot.101: 901-907.

Nielsen TM, Deiting U, Stitt M (1997) A $\beta$ - amylase in potato tubers is induced by storage at low temperature. Plant Physiol. 113: 503-510.

Okamura M (1980) An improved method for determination of L-ascorbic acid and L-dehydroascorbic acid in blood plasma. Clin. Chim. Acta. 103: 259-268.

Olmos E, Hellin E (1997) Cytochemical localization of ATPase plasma membrane and acid phosphatase by cerium based in a salt-adapted cell line of Pisum sativum. J. Exp. Bot. 48: 1529-1535.

Prasad MNV (1995) Cadmium toxicity and tolerance in vascular plants. Environ. Exp. Bot. 35: 525-545. 


\section{ANTIOXIDANT AND OTHER BIOCHEMICAL DEFENSE RESPONSES OF MACROTYLOMA UNIFLORUM (LAM.) \\ VERDE. (HORSE GRAM) INDUCED BY HIGH TEMPERATURE AND SALT STRESS}

Rahnama $\mathrm{H}$, Ebrahimzadeh $\mathrm{H}$ (2005) the effect of $\mathrm{NaCl}$ on antioxidant enzyme activities in potato seedlings. Biol Plantarum 49: 93-97.

Sairam, R K., Tyagi, A. (2004) Physiology and molecular biology of salinity stress tolerance in plants. Current Sci. 86: 407-42.

Scheidig A, Fro hlich A, Schulze S, Lloyd JR, and Kossmann J. (2002) Downregulation of a chloroplast-targeted beta-amylase leads to starchexcess phenotype in leaves. Plant J. 30: 581-59.

Seki M, uchi S, Kobayashi M, Taji T, Naramoto M, Kato T, Tabata S, Kakubari Y, Yamaguchi-Shinozaki K, Shinozaki K (2001) Regulation of drought tolerance by gene manipulation of 9-cis-epoxycarotenoid dioxygenase a key enzyme in abscisic acid biosynthesis in Arabidopsis. Plant J. 27: 325-333.

Shao HB, Chu LY, Lu ZH, Kang CM (2008) Primary antioxidant free radical scavenging and redox signaling pathways in higher plant cells. Int. J. Biol. Sci. 4: 8-14.

Shigeoka S, Ishikawa T, Tamoi M, Miyagaw Y, Takeda T, Yabuta Y, Yoshimura K (2002) Regulation and function of ascorbate peroxidase isoenzymes. J. Expt. Bot. 53: 1305-1319.

Shuster L, Gifford RH (1962) Assay of a/b amylases. Arch. Biochem. Biophys. 194: 534-540.

Sung DY, Vierling E, Guy CL, (2001) Comprehensive expression profile analysis of the Arabidopsis Hsp70 gene family. Plant Physiol. 126: 789-800.
Szabo-Nagy AG, Galiba G, Erdei E (1992) Induction of soluble phosphatases under ionic and non-ionic, osmotic stress in wheat. J. Plant Physiol. 140: 329-633.

Tsai CC, Chen HS, Chen SL, Ho YP, Ho KY, Wu YM, Hung CC ( 2005) Lipid peroxidation : a possible role in the induction and progression of chronic periodontitis. J Periodont Res 40: 378-384.

Unyayar S, Kele SY, Ceki CO (2005) The antioxidative response of two tomato species with different drought tolerances as a result of drought and cadmium stress combinations. Plant Soil Environ. 51: 57-64.

Velikova V, Yordanov I, Edreva A (2000) Oxidative stress and some antioxidant systems in acid rain-treated bean plants, Protective role of exogenous polyamines. Plant Sci. 151: 59-66.

Waheed A, Gelani S, Ashraf M, Foolad MR (2007) Heat tolerance in plants: An overview. Environ. Exp. Bot. 61: 199-223.

Xu S, Li J, Zhang X, Wei H, Cui L (2006) Effects of heat acclimation pretreatment on changes of membrane lipid peroxidation, antioxidant metabolites, and ultrastructure of chloroplasts in two cool-season turfgrass species under heat stress. Environ. Exp. Bot. 56: 274-285.

Yang KY, Liu Y, Zhang S (2001) Activation of a mitogenactivated protein kinase pathway is involved in disease resistance in tobacco. Proc. Natl. Acad. Sci. USA. 98: 741-746. 